\title{
Influence of photoperiod on the seasonal pattern of secretion of luteinizing hormone and testosterone and on the antler cycle in roe deer (Capreolus capreolus)
}

\author{
A. J. Sempéré ${ }^{1}$, R. Mauget ${ }^{1}$ and G. A. Bubenik ${ }^{2}$ \\ ${ }^{1}$ Centre d'Etudes Biologiques de Chizé (CNRS) F-79360 Villiers en Bois, France; and ${ }^{2}$ Department \\ of Zoology, College of Biological Science, University of Guelph, Ontario, \\ Canada, NIG $2 \mathrm{Wl}$
}

\begin{abstract}
Summary. Annual variations in concentrations of luteinizing hormone (LH) and testosterone in plasma were analysed in relation to the antler cycle in six adult male roe deer exposed to a natural photoperiod (latitude $46^{\circ} 10^{\prime} \mathrm{N}$ ) and in four adult males maintained in a constant short-day photoperiod $(8 \mathrm{~h}$ light: $16 \mathrm{~h}$ dark) for a year, from the winter solstice at which time both groups of animals had antlers in velvet. The animals were sampled, every $15 \mathrm{~min}$ for 2 or $4 \mathrm{~h}$ at intervals of one month for a year. Under both natural and experimental conditions, LH concentrations were high from January to March, but in the experimental conditions they decreased between April and May-June, whereas in the natural conditions they increased. Plasma LH concentration was lowest between July and November in animals under natural photoperiod, whereas under $8 \mathrm{~h}$ light: $16 \mathrm{~h}$ dark photoperiod a second increase in plasma LH occurred between August and September. Between March and August, concentrations of plasma testosterone increased under natural photoperiod, whereas under experimental photoperiod there was a biphasic pattern of plasma testosterone with peaks between February and May and between September and November. Under natural photoperiod, antlers were cast in November, $369 \pm 6$ days after the previous antlers were cast. Under experimental photoperiod, antlers were cast after $193 \pm 10$ days, and a new set developed. The sexual cycle of the male appears to be initiated by an endogenous rhythm in winter and is then maintained by hormonal changes resulting from increasing photoperiod in spring. The modified antler cycle and the patterns of plasma LH and of testosterone concentrations suggest that this rhythm has a period of about 6 months.
\end{abstract}

Ke' 'words: LH; testosterone; antlers; photoperiod; roe deer

\section{Introduction}

In many temperate zone cervids, increased gonadotrophin secretion, testicular activity and reproductive activity occur while daylengh is decreasing (Lincoln, 1985). In male white tailed deer, Odocoileus virginianus, and in fallow deer, Dama dama, pituitary gonadotrophin activity which provokes and sustains sexual activity is high for 4 or 5 months (Lincoln \& Kay, 1979; Bubenik et al., 1982; Bubenik, 1986; Asher et al., 1989) and, in male red deer, Cervus elaphus, for 2 months before the autumn rut (Lincoln \& Kay, 1979). Roe deer which mate in summer rather than in autumn with a 7 month period of sexual activity (Bramley, 1970; Sempéré, 1982, 1990) exhibit highest seasonal concentrations of serum luteinizing hormone (LH) in spring when daylength is increasing (Schams \& Barth, 1982; Sempéré \& Lacroix, 1982). 
Roe deer may differ from white tailed deer and fallow deer in that the seasonal increase in gonadotrophin secretion may be a consequence of increasing rather than decreasing daylength. In some temperate zone cervids, manipulation of photoperiod affects the timing of the breeding cycle (Jaczewski, 1954; Goss, 1983; Bubenik et al., 1987; Suttie et al., 1989) and this study of roe deers was designed to determine whether increasing photoperiod is necessary for the initiation of reproductive activity, defined by changes in the concentrations of plasma $\mathrm{LH}$, testosterone and in the pattern of antler casting. Adult males were transferred to constant short days starting at the winter solstice while control animals were maintained outdoors.

\section{Material and Methods}

\section{Animals \\ Control animals}

Six adult males ( 24 years old) were kept under natural photoperiod in small paddocks at the Centre d'Etudes Biologiques des Animaux Sauvages, CNRS (France, $46^{\circ} 10^{\prime} \mathrm{N}, 0^{\prime} 30^{\prime} \mathrm{E}$ ). Natural grazing was supplemented with sheep pellets, forage and apples. Adjoining the paddocks were the handling facilities. Opportunistic observations were made with a view to recording the onset of rutting behaviour (Bramley, 1970).

\section{Experimental animals}

Four adult males were transferred from paddocks to pens in light-proof rooms and were exposed over a period of

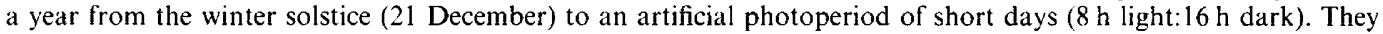
were fed ad libitum with sheep pellets, forage, fresh leaves and apples. Antler status (casting period, antlers in velvet, polished antlers) was recorded daily. Behavioural studies were not possible owing to the conditions of confinement.

\section{Blood sampling}

The animals were captured once a month. Particular care was taken to minimize the stress of capture. Animals were gently moved from the fodder area through a darkened shed (controls) and into an adjacent darkened room (experimental animals) and thence into trap boxes where they were sedated (intramuscular Rompun, xylazine hydrochloride (Bayer, Leuerkusen) at a dose of $1 \mathrm{mg} \mathrm{kg}^{-1}$ and ketamine, $2 \mathrm{mg} \mathrm{kg}^{-1}$; Rhône Mérieux, Lyon) and cannulated. Sedation was maintained with sequential administrations of Rompun and ketamine. Choice of sedative is important as some drugs like etorphine and acepromazine abolish episodic fluctuations of LH (Peet \& Lincoln, 1977). In ewes, ketamine $\left(6 \mathrm{mg} \mathrm{kg}^{-1}\right)$ did not significantly affect LH concentrations (Clarke \& Doughton, 1983) and Rompun, alone or with ketamine, has been found satisfactory for use in studies of cervid reproduction (van Mourik \& Stelmalsiak, 1985; Bubenik et al., 1987, Fennessy et al., 1988; Suttie et al., 1989).

At each monthly capture, blood samples were collected every $15 \mathrm{~min}$ for $2 \mathrm{~h}$, and the mean concentrations of LH and testosterone were obtained for each animal. Additionally, from December to late August, two control and two experimental males $(8 \mathrm{~h}$ light: $16 \mathrm{~h}$ dark) were sampled every $15 \mathrm{~min}$ for a total of $4 \mathrm{~h}$ for detection and analysis of pulsatile LH secretion. After removal of the cannula, $2 \mathrm{ml}$ of antibiotic was given. Blood samples were centrifuged for $15 \mathrm{~min}$ at $1500 \mathrm{~g}$ immediately after collection and the plasma was stored at $-20^{\circ} \mathrm{C}$ until assayed.

\section{Hormone assays}

Plasma testosterone concentrations were determined in duplicate by non-chromatographic radioimmunoassay (Sempéré \& Boissin, 1983). The antiserum used in the assay (INRA-Nouzilly, France) was developed in rabbit against a testosterone (3-0-carboxymethyl)-oxine BSA conjugate and used at a final dilution of 1:75000. The ${ }^{3}[\mathrm{H}]$ testosterone $\left(3.33 \mathrm{TBq} \mathrm{mmol}^{-1}\right)$, was supplied by CEA-Saclay, France. Sensitivity was $6.25 \mathrm{pg}$ per tube $\left(60 \mathrm{pg} \mathrm{m}{ }^{-1}\right)$. At the $50 \%$ displacement level for $50 \mathrm{pg}$ testosterone per tube, crossreactivities were as follows: $5 \alpha$ dihydrotestosterone $17.8 \% ; 5 \beta$-androstane- $3 \beta$ and $17 \beta$-diol $1.4 \% ; 5 \alpha$-androstane and $3 \beta$-17 3 -diol $1.2 \%$; androstenadione $1.4 \%$; epitestosterone $0.7 \%$; progesterone $0.07 \%$; cholesterol, dehydroepiandrosterone, cortisol deoxycorticosterone and oestradiol $<0.02 \%$. The mean recovery from extracts of plasma from deer was $90.2 \pm 0.2 \%$ ( \pm SEM). Coefficients of variation were $12 \%$ (interassay) and $7 \cdot 1 \%$ intra-assay).

Plasma concentrations of LH were determined in a single assay to eliminate interassay variability. Samples were analysed in duplicate by heterologous radioimmunoassay (Sempéré \& Lacroix, 1982) using LH M3, which has as standard 1.5 times the activity of NIH-LH-SI (Jutisz \& Courte, 1968). The antiserum did not crossreact with ovine FSH, GH or TSH. Assay sensitivity was $0.2 \mathrm{ng} \mathrm{ml}^{-1}$ and the intra-assay cocfficient of variation was less than $5 \%$.

\section{Statistical analysis}

The mean concentrations of testosterone and $\mathrm{LH}$ were expressed with their standard errors. Statistical comparisons between each monthly mean value of each hormone were carried out by analysis of variance. 
Gonadotrophin pulses were identified as described by Goodman \& Karsch (1980). The criterion for definition of a peak was its occurrence within two samples of the preceding nadir. The amplitude (peak minus nadir) had to be greater than the sensitivity of the LH assay and had to exceed the $95 \%$ confidence limits of the preceding nadir.

\section{Results}

\section{Reproductive and antler cycle in animals under natural photoperiod}

The highest plasma LH concentrations were recorded in January-February (Fig. 1). After a significant decrease in March-April $(P<0.001)$ concentrations increased again in May-June $(P<0.05)$ and then dropped significantly to minimum values in July-August $(P<0.001)$. Rutting behaviour was observed at this time. A significant increase in plasma LH concentrations was observed between August and September $(P<0 \cdot 001)$. The lowest plasma testosterone concentrations were observed from October to January. They rose significantly in February $(P<0.05)$ and after remaining high from March to May increased to their maximum values in July, during the rut. A significant decrease of testosterone was recorded in August $(P<0.01)$. Minimum concentrations were reached in October and persisted until January.
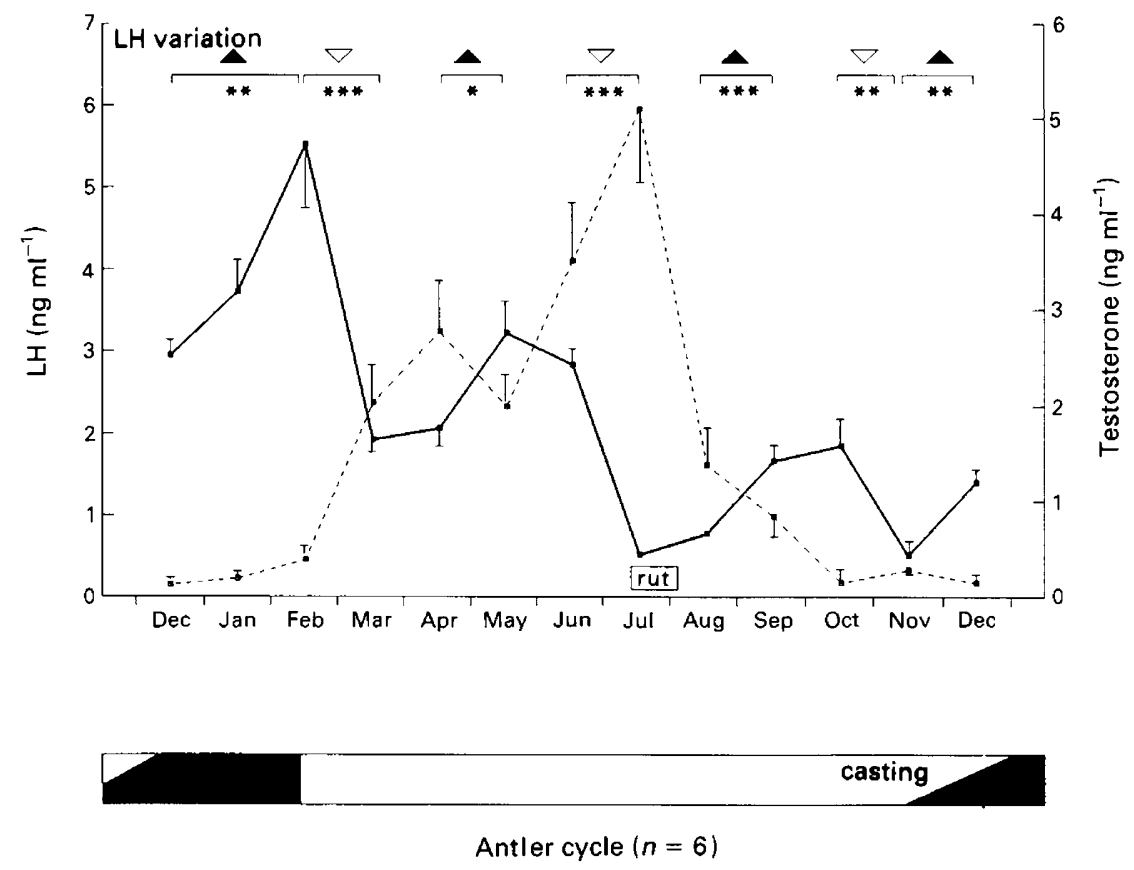

Fig. 1. Annual variations in concentrations of plasma luteinizing hormone $(\mathrm{LH})(-$ and testosterone (-- ) and antler development in six adult male roe deer exposed to a natural photoperiod $\left(46^{\circ} 10^{\prime} \mathrm{N}\right)$. ( $\square$ ) hard antlers, ( $\square$ ) velvet. Monthly LH concentrations represent the mean for all animals of nine samples per animal during $2 \mathrm{~h}$; significant increase $(\boldsymbol{\Delta})$ and decrease $(\nabla)$ of LH concentrations as determined by analysis of variance $\left(F\right.$ test): ${ }^{*} P<0 \cdot 05$; ${ }^{* *} P<0.005 ;{ }^{* * *} P<0.001$.

All the animals had cast their antlers by mid-November when plasma testosterone concentrations were low. After casting, new antlers in velvet started to grow immediately. The antlers were fully developed in February and completely polished (stripped of velvet) in early March. The period of the antler cycles measured between dates on which antlers were cast was $369 \pm 6$ days. 


\section{Reproductive and antler cycle in experimental animals $(8 \mathrm{~h}$ light:16 h dark)}

As in control animals, high plasma LH concentrations were recorded in January (Fig. 2), but in experimental deer, high LH concentrations were maintained until April and then decreased significantly to a minimum in May-June $(P<0.01)$, at a time when controls exhibited a significant increase of LH (Fig. 1). A second LH peak $(P<0.001)$ was observed in August-September. Testosterone concentrations were high from February to May then dropped significantly $(P<0.05)$ to basal values in June-July, a time when the highest testosterone concentrations were recorded in control animals (Fig. 1). The experimental animals dropped their antlers in June or July and antler regrowth recommenced. Plasma testosterone concentration increased for the second time from August to November, decreasing again in December $(P<0.05)$, when antlers were cast. Animals therefore exhibited two complete cycles of antler casting within a period of $193 \pm 10$ days.
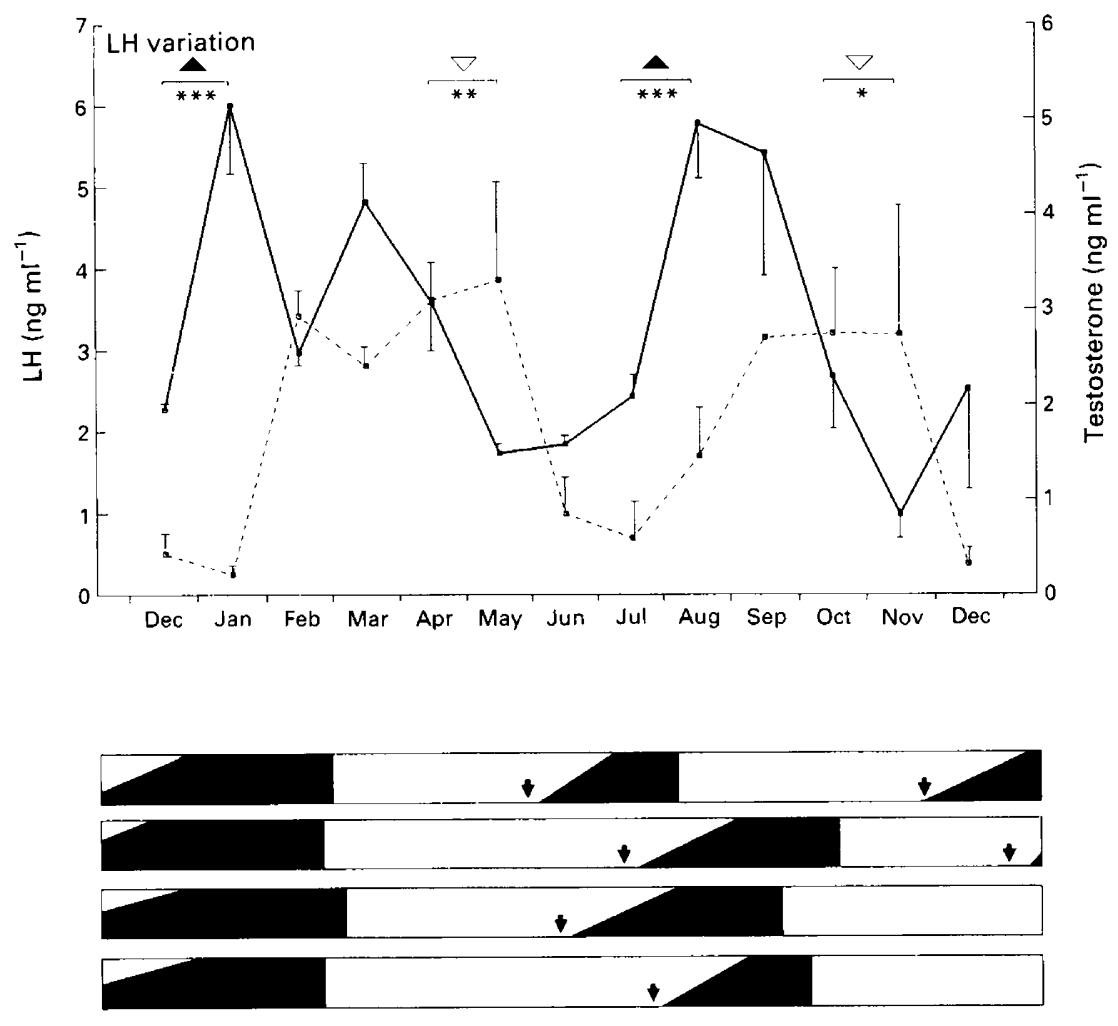

Antler cycle

Fig. 2. Annual variations of plasma luteinizing hormone ( $\mathrm{LH})(-)$ and testosterone (-- ) concentrations and antler development in four adult male roe deer maintained under constant short days ( $8 \mathrm{~h}$ light:16 h dark). ( $\square$ ) hard antler; ( $\boldsymbol{\square}$ ) velvet. Monthly LH concentrations represent the mean for all animals of nine samples per animal during $2 \mathrm{~h}$; significant increase $(\boldsymbol{\Delta})$ and decrease $(\nabla)$ of $\mathrm{LH}$ concentrations as determined by analysis of variance $(F$ test): ${ }^{*} P<0.05 ; * * P<0.005 ;{ }^{* * *} P<0.001$.

\section{LH release patterns in control and experimental animals}

A high frequency pattern of pulsatile LH release was detected in the blood of control and experimental animals between December and February (Table 1). Thereafter, between March and August, $\mathrm{LH}$ release did not follow the same pattern. In experimental animals, the frequency of 
LH pulses remained high in March-April, but decreased in May-June. In control animals the frequency of LH pulses remained high until June and was significantly higher $(P<0.05)$ in May-June than in experimental animals. In August, no LH pulses were detected in control animals whereas in experimental males the pulse frequency was at its maximum. No significant difference in the amplitude of LH pulses was found throughout the study in experimental or control animals. There was no direct relationship between each LH pulse and testosterone secretion during the $4 \mathrm{~h}$ sampling periods (Fig. 3). There was no evidence for a pulsatile pattern of testosterone secretion.

Table 1. Frequency and amplitude of luteinizing hormone pulses occurring during each $4 \mathrm{~h}$ sampling period for two control male roe deer exposed to natural lighting and two experimental animals maintained on short days ( $8 \mathrm{~h}$ light: $16 \mathrm{~h}$ dark) from the winter solstice

\begin{tabular}{|c|c|c|c|c|c|c|c|c|}
\hline \multirow[b]{2}{*}{ Month } & \multicolumn{4}{|c|}{ Controls } & \multicolumn{4}{|c|}{$8 \mathrm{~h}$ light: $16 \mathrm{~h}$ dark } \\
\hline & $n_{1}$ & $\begin{array}{c}\text { LH pulse } \\
\text { frequency* } \\
\text { (number in } 4 \mathrm{~h} \text { ) }\end{array}$ & $\begin{array}{l}\text { LH pulse } \\
\text { amplitude } \\
\left(\mathrm{ng} \mathrm{ml} \mathrm{m}^{-1}\right)\end{array}$ & $n_{2}$ & $n_{1}$ & $\begin{array}{c}\text { LH pulse } \\
\text { frequency } \\
\text { (number in } 4 \mathrm{~h} \text { ) }\end{array}$ & $\begin{array}{l}\text { LH pulse } \\
\text { amplitude } \\
\left(\mathrm{ng} \mathrm{ml}^{-1}\right)\end{array}$ & $n_{2}$ \\
\hline Dec Jan Feb & 6 & $2 \cdot 00 \pm 0 \cdot 24^{\mathrm{a}}$ & $4.43 \pm 0.49$ & 12 & 6 & $2 \cdot 00 \pm 0 \cdot 24^{\mathrm{a}}$ & $6.49 \pm 1.49$ & 16 \\
\hline $\mathrm{Mar}-\mathrm{Apr}$ & 4 & $0.75 \pm 0.4 \mathrm{I}^{\mathrm{a}}$ & $5.17 \pm 1.37$ & 3 & 4 & $2 \cdot 50 \pm 0.25^{\mathrm{b}}$ & $7.76 \pm 1.52$ & 11 \\
\hline May-June & 4 & $2 \cdot 25 \pm 0.54^{\mathrm{a}}$ & $4.98 \pm 0.87$ & 13 & 4 & $0.50 \pm 0.25^{\mathrm{b}}$ & $2 . \overline{65}$ & 2 \\
\hline Jul Aug & 4 & 0.00 & & & 4 & $2.75 \pm 0.54$ & $6.78 \pm 0.80$ & 15 \\
\hline
\end{tabular}

All animals were sampled every $15 \mathrm{~min}$ for $4 \mathrm{~h}$ (beginning at $10 \cdot 00 \mathrm{~h}$ ).

* LH pulse frequency represents the mean number $( \pm$ SEM) of LH peaks in $4 \mathrm{~h}$ per animal.

+LH amplitude expressed as the mean incremental changes in plasma concentration per LH pulse ( \pm SEM).

$n_{1}$ : number of sampling periods (equal to number of animals $\times$ number of months).

$n_{2}$ : number of LH peaks in all series of observations combined.

Values in the same row with different superscript letters differed significantly $(P<0.05)$.

\section{Discussion}

The general model for the interaction between $\mathrm{LH}$ and testosterone is that the former stimulates production of the latter. Males of seasonally breeding mammals such as Soay sheep (Lincoln, 1976), red deer (Lincoln \& Kay, 1979) and fallow deer (Asher et al., 1989), during the period of reactivation of the reproductive system, show high amplitude LH pulses, but only minor increases in plasma testosterone. At the peak of testicular activity, there are major fluctuations in testosterone, which suppress the amplitude of LH pulses through a negative feedback mechanism (Fennessy et al., 1988). Earlier studies (Schams \& Barth, 1982; Sempéré \& Lacroix, 1982) have indicated that roe deer conform to this general model, though studies of the pulsatile pattern of hormone release have not been published.

While their antlers are growing in winter, male roe deer exhibit high mean LH concentrations with high pulse frequency, accompanied by low testosterone concentrations. While the antlers are being cleaned of velvet (February-March), the concentration of testosterone rises, and that of LH falls, whereas LH pulse frequency decreases. As the rut approaches, i.e. in May and June, plasma testosterone concentration increases and LH pulse frequency increases, but once the rut starts in July, when plasma testosterone is maximal, LH has fallen to minimum concentrations and we could not detect an LH pulse. In red deer and in fallow deer (Lincoln \& Kay, 1979; Asher \& Peterson, 1991) at the time of the rut there was, similarly, episodic secretion of testosterone with no pulsatile secretion of LH. In these species the testis appears to be much more responsive to $\mathrm{LH}$ at this time (Suttie et al., 1984), and it certainly appears that in roe deer, in the rut, increased testosterone concentrations inhibit LH release but not sufficiently to inhibit steroidogenesis. Further support for 
(a)
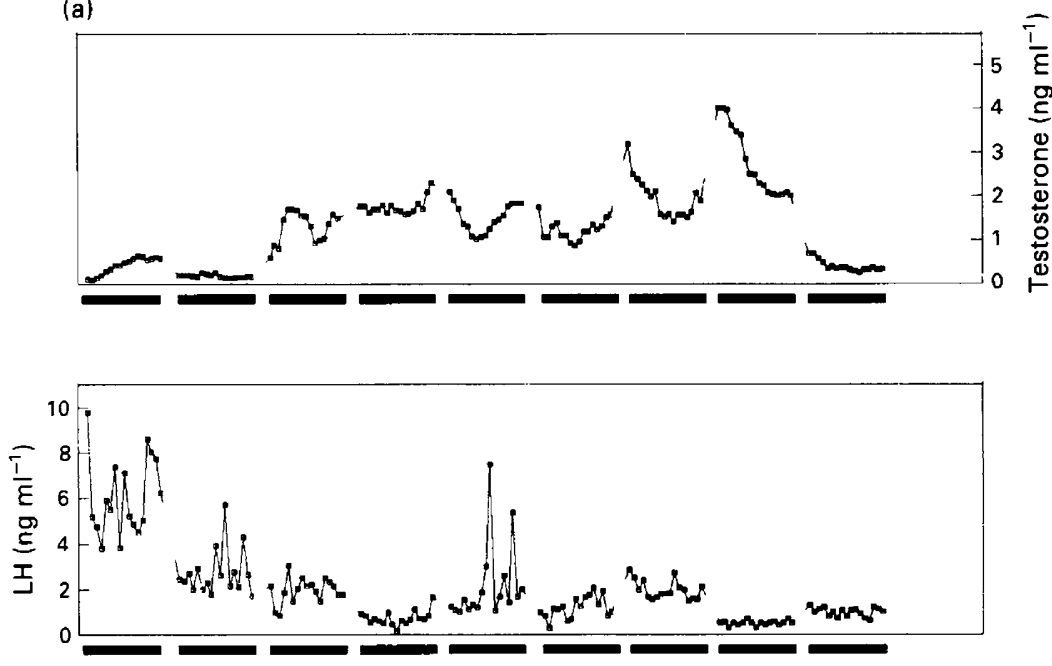

(b)
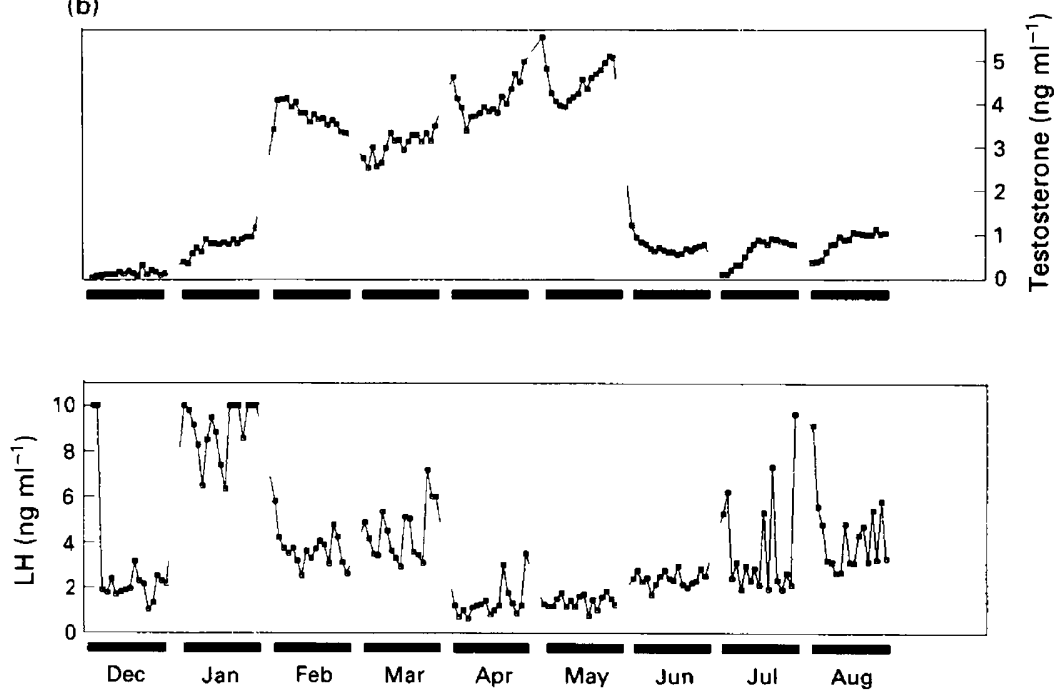

Fig. 3. Monthly $4 \mathrm{~h}$ individual profiles of concentration of luteinizing hormone (LH) and testosterone in plasma in (a) control male roe deer exposed to natural photoperiod and (b) experimental animal held on $8 \mathrm{~h}$ light: $16 \mathrm{~h}$ dark photoperiod from the winter solstice.

this hypothesis comes from studies (Suttie et al., 1984; Sempéré et al., 1992) in which GnRH, administered monthly throughout the year, induced a relatively smaller release of LH but a much larger consequential increase of testosterone, during the rut.

Our experimental animals were transferred to a $8 \mathrm{~h}$ light: $16 \mathrm{~h}$ dark photoperiod at the winter solstice, but the pattern of LH and testosterone secretion from January to March was the same as that observed under natural photoperiod. This could therefore be an expression of an endogenous rhythm, and there are several examples of spontaneous testis or antler cycles in animals under constant photoperiod (Lincoln \& Short, 1980; Howles et al., 1982; Goss, 1983). Further study is 
required to determine whether this could have been entrained by photoperiodic experience, as has been noted in ewes (Robinson \& Karsch, 1987; Foster et al., 1988; O'Callaghan et al., 1991).

Animals under constant $8 \mathrm{~h}$ light: $16 \mathrm{~h}$ dark photoperiod did not show the April-May peak in LH observed in controls, which has previously been noted (Schams \& Barth, 1982; Sempére \& Lacroix, 1982) when daylength is over $12 \mathrm{~h}$. The casting of antlers in June-July, five months earlier than was observed in animals under natural photoperiod, is presumably a result of this, in that a fall of testosterone concentration precipitates antler casting in other deer (Suttie et al., 1984; Fennessy et al., 1988) and such a fall would be induced by declining LH concentrations.

The new antler cycle that began immediately after antlers were cast by the deer kept under $8 \mathrm{~h}$ light: $16 \mathrm{~h}$ dark photoperiod was associated with increases in $\mathrm{LH}$ and testosterone concentration and in frequency of the LH pulses. These increases together with the January peaks could be the expression of an endogenous rhythm of approximately six months.

We suggest that in roe deer there is an endogenous rhythm in LH and testosterone secretion, with a period of about 6 months, which is responsible for the start of increased secretion of these hormones in January. Evidently LH secretion cannot continue to be sustained after March without the stimulus of days over $12 \mathrm{~h}$ in length. It is this second phase of $\mathrm{LH}$ secretion, that, through its effect on testosterone secretion, maintains the antlers and induces rutting behaviour in July-August in wild roe deer.

Under natural photoperiod LH shows a resurgence in September and October and then falls in November. Under constant $8 \mathrm{~h}$ light: $16 \mathrm{~h}$ dark photoperiod, there is also a peak of $\mathrm{LH}$ at this time with a subsequent fall precisely coincident with that observed under natural photoperiod. We suggest that these phenomena also represent an expression of the proposed endogenous rhythm. This suggestion is supported by our observations (Sempéré et al., 1992) that the pattern of response of LH secretion to a standard monthly dose of GnRH follows the same pattern of increase from August to October and decline to December.

The authors thank A. Lacroix for performing the hormone assays, and Z. Marillet and C. Trouve for the skilled technical assistance. We gratefully acknowledge N. Guillon for assistance with blood sampling and animal care and Mr Suire (Mounet C.A.S.A.) for providing food for the animals. We wish to thank $\mathrm{C}$. Mauget for computer programming and manuscript preparation. We gratefully acknowledge S. J. G. Hall and two anonymous reviewers for help in improving the manuscript.

\section{References}

Asher, G.W. \& Peterson, A.J. (1991) Pattern of LH and testosterone secretion of adult male fallow deer (Dama dama) during the transition into the breeding season. Journal of Reproduction and Fertility 91, 649654 .

Asher, G.W., Peterson, A.J. \& Bass, J.J. (1989) Seasonal pattern of $\mathrm{LH}$ and testosterone secretion in adult male fallow deer (Dama dama). Journal of Reproduction and Fertility 85, 657. 665.

Bramley, P.S. (1970) Territoriality and reproductive behaviour of roe deer. Journal of Reproduction and Fertility Supplement 11, 43-70.

Bubenik, G.A. (1986) Regulation of seasonal endocrine rhythms in male boreal cervids. In Endocrine Regulation as Adaptive Mechanisms to the Environment, pp. 461-474. Eds I. Assenmacher \& J. Boissin. CNRS-CEBAS, France.

Bubenik, G.A., Morris, J.M., Schams, D. \& Claus, A. (1982) Photoperiodicity and circannual levels of LH, FSH, and testosterone in normal and castrated male while-tailed deer. Canadian Journal of Physiology and Pharmacology 60, 788-793.

Bubenik, G.A., Schams, D. \& Coenen, G. (1987) The effect of artificial photoperiodicity and antiandrogen treatment on the antler growth and plasma levels of LH, FSH, testosterone, prolactin and alkaline phosphatase in the male white-tailed deer. Comparative Biochemistry and Physiology 87A, 551-559.

Clarke, I.J. \& Doughton, B.W. (1983) Effect of various anaesthetics on resting plasma concentrations of luteinizing hormone, follicle-stimulating hormone and prolactin in ovariectomized ewes. Journal of Endocrinology 98, 79-89.

Fennessy, P.F., Suttie, J.M., Crosbie, S.F., Corson, I.D., Elgar, H.J. \& Lapwood, K.R. (1988) Plasma LH and testosterone responses to gonadotrophin-releasing hormone in adult red deer (Cervus elaphus) stags during the annual antler cycle. Journal of Endocrinology 117, 35-41. 
Foster, D.L., Yellon, S.M., Ebling, F.J.P. \& Claypool, L.E. (1988) Are ambient short-day cues necessary for puberty in a short-day breeder? Biology of Reproduction 38, 821-829.

Goodman, R.L. \& Karsch, F.J. (1980) Pulsatile secretion of luteinizing hormone: differential suppression by ovarian steroids. Endocrinology 107, 1286-1290.

Goss, R.J. (1983) Deer antlers. Regeneration, function and evolution. Academic Press, New York.

Howles, C.M., Craigon, J. \& Haynes, N.B. (1982) Longterm rhythms of testicle volume and plasma prolactin concentrations in rams reared for 3 years in constant photoperiod. Journal of Reproduction and Fertility $65,439-446$.

Jaczewski, Z. (1954) The effect of altered daylight on the growth of antlers in the deer (Cervus elaphus). Folia Biologica II, 133-I43.

Jutisz, M. \& Courte, C. (1968) Hormone luteinizante (LH) de mouton. I. Obtention à l'état apparemment homogène. Etude physicochimique et biologique. General and Comparative Endocrinology 11, 562-574.

Lincoln, G.A. (1976) Secretion of LH in rams exposed to two different photoperiods. Journal of Reproduction and Fertility 47, 351-353.

Lincoln, G.A. (1985) Seasonal breeding in deer. Royal Society of New Zealand Bulletin 22, 165-179.

Lincoln, G.A. \& Kay, R.N. (1979) Effects of season on the secretion of $\mathrm{LH}$ and testosterone in intact and castrated red deer stags (Cervus elaphus). Journal of Reproduction and Fertility 55, 75-80.

Lincoln, G.A. \& Short, R.V. (1980) Seasonal breeding: nature's contraceptive. Recent Progress in Hormone Research 36, 1-52.

O'Callaghan, D., Karsch, F.J., Boland, M.P. \& Roche, J.F. (1991) Role of short days in timing the onset and duration of reproductive activity in ewes under artificial photoperiods. Biology of Reproduction 44, $23-28$

Peet, M.J. \& Lincoln, G.A. (1977) Blockade of episodic gonadotrophin secretion by Immobilon in ovariectomized ewes. Journal of Reproduction and Fertility 50, $97-100$.

Robinson, J.E. \& Karsch, F.J. (1987) Photoperiodic history and a changing melatonin pattern can determine the neuroendocrine response of the ewe to daylength. Journal of Reproduction and Fertility 80, 159-165.

Schams, D. \& Barth, D. (1982) Annual profiles of reproductive hormones in peripheral plasma of the male roe deer (Capreolus capreolus). Journal of Reproduction and Fertility 66, 463468.

Sempéré, A.J. (1982) Fonction de reproduction et caractères sexuels chez le chevreuil (Capreolus capreolus L.): Variations saisonnières secondaires et incidences sur l'utilisation du budget temps-espace. Thêse Doct. ès Sci, Université de Tours, Tours, France.

Sempéré, A.J. (1990) The annual antler cycle of the European Roe Deer (Capreolus capreolus) in relationship to the reproductive cycle. In Horns and Antlers, pp. $396-415$. Eds A. B. Bubenik \& G. A. Bubenik. Springer-Verlag, New York.

Sempéré, A.J. \& Boissin, J. (1983) Neuroendocrine and endocrine control of testicle activity and the antler cycle from birth to aduithood in the male roe deer (Capreolus capreolus L.). In Antler Development in Cervidae, pp. 109-122. Ed. R. D. Brown. Caesar Kleber Wildlife Research Institute, Kingsville, Texas.

Sempéré, A.J. \& Lacroix, A. (1982) Temporal and seasonal relationship between $\mathrm{LH}$, testosterone and antlers in fawn and adult male roe deer. Acta Endocrinologica (Copenhagen) 99, 295-301.

Sempéré, A.J., Mauget, R. \& Lacroix. A. (1992) Seasonal regulation of the sexual cycle and antler growth in roe deer: evidence for an endogenous rhythm. Second International Symposium on Cervids, pp. 499-504. Ed. R. D. Brown. Springer-Verlag, New York.

Suttie, J.M., Lincoln, G.A. \& Kay, R.N.B. (1984) Endocrine control of antler growth in red deer stags. Journal of Reproduction and Fertility 71, 7-15.

Suttie, J.M., Fennessy, P.F., Corson, I.D., Laas, F.J., Elgar, H.J. \& Lapwood, K.R. (1989) LH and testosterone responses to GnRH in red deer (Cervus elaphus) stags kept in a manipulated photoperiod. Journal of Reproduction and Fertility 85, 213-219.

Van Mourik, S. \& Stelmalsiak, T. (1985) Seasonal variation in plasma prolactin concentration in adult male rusa deer (Cervus rusa timorensis). Comparative Biochemistry and Physiology 82A, 323-328. 